\title{
Tech-Assisted Language Learning Tasks in an EFL Setting: Use of Hand phone Recording Feature
}

\author{
Alireza Shakarami (Corresponding author) \\ Department of English, Kazerun Branch, Islamic Azad University, Kazerun, Iran \\ E-mail: shahkarami_alireza@yahoo.com \\ Hassan Khajehei \\ Department of English, Kazerun Branch, Islamic Azad University, Kazerun, Iran \\ Karim Hajhashemi \\ School of Education, James Cook University, Cairns, Australia
}

Received: 08-03-2014

doi:10.7575/aiac.ijalel.v.3n.5p.100
Accepted: 04-05-2014

Published: 01-09-2014

\begin{abstract}
Technology with its speedy great leaps forward has undeniable impact on every aspect of our life in the new millennium. It has supplied us with different affordances almost daily or more precisely in a matter of hours. Technology and Computer seems to be a break through as for their roles in the Twenty-First century educational system. Examples are numerous, among which CALL, CMC, and Virtual learning spaces come to mind instantly. Amongst the newly developed gadgets of today are the sophisticated smart Hand phones which are far more ahead of a communication tool once designed for. Development of Hand phone as a wide-spread multi-tasking gadget has urged researchers to investigate its effect on every aspect of learning process including language learning. This study attempts to explore the effects of using cell phone audio recording feature, by Iranian EFL learners, on the development of their speaking skills. Thirty-five sophomore students were enrolled in a pre-posttest designed study. Data on their English speaking experience using audio-recording features of their Hand phones were collected. At the end of the semester, the performance of both groups, treatment and control, were observed, evaluated, and analyzed; thereafter procured qualitatively at the next phase. The quantitative outcome lent support to integrating Hand phones as part of the language learning curriculum.
\end{abstract}

Keywords: Hand phone, Recording, Audio, Language learning, Enhancement, EFL

\section{Background}

Many studies are conducted worldwide on cell-phones and their effects on various educational subject matters. Some have focused on the language skills including reading comprehension, vocabulary, and listening comprehension; whereas others have conducted studies on the phones functional capabilities like audio-visual recordings. In a study by Uzunboylu, Cavus, and Ercag (2009), camera features were used to keep track of the environmental changes occurring in the users' areas. In another study by Gromik's (2009), learners were asked to use audio recording feature to record their ideas and views on topics important to them. Also, it was concluded in some reported studies that such cell phone recording features contributed to the promoted identity development and better understanding of the users' surroundings. They opine that students put high value on the photos and recording features of their Hand phones and its use to report and share content over the Internet. Research about Mobile Assisted Language Learning is considerable and include investigations of the related issues with regard to the use of Tablet PC, mp3 technology, PDAs and Hand phones, to mention a few. Nearly, all the university and college students of the new millennium are Hand phone users and that is the main reason this study looks into the use of Hand phone rather than other less prevailing gadgets, as a facilitating instrument in the language learning tasks. The current study aims to manipulate students' familiarity with, and interest in their Hand phone audio-visual features in order to identify its probable impact on the enhancement of English language skills learning. The participants have to use their mobile phone to make a voice recording about topics of interest to them. In doing so, students use their mobile phones as a device to produce materials and communicate their views in L2 at their desired times. The learners are dependent more or less on their L2 background and vocabulary knowledge for comprehension of the context.

\section{What the Literature Say}

Reports of Oliver and Goerke (2008), Motiwalla (2007), Pouezevara and Khan (2007) and Shudong and Higgins (2005) showed that improvements in technology and practical applications still are necessary to make mobile phone the right platform for providing education materials to students . Based on their findings, they argue that, as any kind of learning primarily requires effort and attention on the part of learners; most people probably would not prefer to learn through the phone, because it is primarily designed for communication. They argue that "people do not have the necessary 
motivation to consistently use mobile learning" (Shudong \& Higgins, 2005, p. 4). The authors further commented that the surrounding environment can be a source of disruption for students and that the examination through the mobile phone can be complicated to implement. They additionally point to the limited memory capacity of mobile phones, slow browsing speed, and the small screen size as factors that make Hand phone learning uncomfortable. In their opinion, the limitations of Hand phone features reduce the productivity of offline self-learning. Finally, they assert that using mobile phones does not replace learning; they just serve you as a new tool for learning.

Some researchers as Shudong and Higgins' (2005)claim that the technology is not yet compatible with the standard required for educational purposes. Stockwell(2010) asserts that learning vocabulary on the Hand phones is not yet desired by the learners. Nevertheless, the findings by Kiernan and Aizawa(2004), Thornton and Houser (2005), as well as Gromik(2009) and Stockwell(2007, 2008, 2010) provide convincing evidence that Hand phones can be a valuable handy instrument for enhancing learning. Much of the research conducted with Hand phones focus on reading, vocabulary acquisition, listening and viewing comprehension. However, the present study suggests that instead of evaluating language acquisition success as language reproduction, it is advisable to test students' performances.

The objective was to encourage English learners to use their Hand phones to record their own sound while speaking about an already-discussed topic, proposing that if a study could combine the benefits of audio features with task-based learning and independent learning, then a method of learning and teaching utilizing Hand phone technology could be introduced. Using this method, students can use their Hand phones to produce content and rely on their speaking ability to express themselves in the target language. The benefit of the method is that students use the target language itself to produce meaningful content in a communicative course.

Hand phones, as the name indicates, has turned to a handy gadget which is always close to the people. New added features to the Hand phones such as their compatibility with different web based software, browsing facility, digital cameras, recording features, availability of online and offline games, and many other features turned it to a multifunctional necessary gadget of the modern life in the new millennium.

\section{Methods}

The present study seeks to unravel the probable role of Hand phone-based audio recording as an effective learning tool for Iranian EFL learners at a university level. The main issue addressed was how Iranian EFL learners can exploit audio recording function of hand phones to increase their competency in verbal communication. The principal reason for using Hand phones rather than other audio devices, was its prevalence and the fact that it is almost always handy to the respondents of the study and also, the existence of option that enables its users to send the recorded audio file(s) to others. In case, respondents remembered or encountered a useful linguistic text or corpus, it can be recorded in a fraction of time and possibly send to their peers of interest.

\subsection{Participants}

Thirty-five sophomore students of English as foreign language in an Iranian university context were selected for the study as they seemed to possess enough English language literacy to fulfill the goals of this research study. They enrolled for Conversation II course and were alphabetically divided into two classes. The first group (class) was assigned as the experimental and the second class as control group respectively. All the respondent students were asked to record a 30 second English audio file, entitled: 'Life as a student' at the commencement of the semester and email it to their instructor (researcher) who taught the two classes. All through the semester, the experimental group members (the second class) were assigned to produce a 30 second recording of verbal reproduction based on topics already discussed in the class in English and email the audio file to the instructor as a weekly assignment for 14 consecutive weeks. They were ensured that grammatical mistakes and slips of the tongue were ignored in order to provide them with the relaxing feeling that they were not scrutinized. The course intended to encourage students to practically produce language in its real sense with no interference on the part of the instructor and to increase students' communicative skills. It was hypothesized that allowing the learners to self-monitor the type of content and oral performance could be an effective step stone to achieve the goal. Each Hand phone recording required students to use retrospective thinking to recall and reflect on the subsets and aspects of topic under discussion, in order to make an oral reproduction. Via this method, it was expected that the students can both have better retention of the materials and topic raised in classroom procedures but concentrate more on the activity and learning task. It was envisaged that the activity would foster the learner's concentration which in turn causes them to spend more time practicing oral skills. The method was supposed to encourage students increase their metacognitive strategies for learning the target language, either by retrieving their prior linguistic knowledge or by developing new required vocabulary knowledge(Gass, 2013).

\subsection{Data Collection Procedure}

Data from the students enrolled in the study were obtained through one semester. Students' Handphone audio recordings were collected and assessed based on fluency and lexical items produced in a second. This analysis sought to identify development during treatment course within the semester, in the experimental group. Data collection was planned over a 14 week semester in a 2 stage schedule. Stage one asked about the respondents' demographic information, hand phone features familiarity, access to computer, and competency in terms of technology and network use. Demographic data were collected based on the Thornton and Houser (2005) framework. In the first stage students were asked to produce first audio recording on their Hand phones. Doing so the researcher learns about possible technical problems, such as non-compatible software, and accordingly considers compensatory strategies. Stage two commenced when all the technical and non-technical encountered problems were resolved. This stage was planned to 
collect students' Hand phone audio recordings from the second to the last week. These recordings were considered more appropriate for the purpose of the study since students were now more familiar with and confident about the assignment and respective process. The recordings were saved as students' audio recording-based speaking performance in the target language and included weekly Hand phone audio assignments to generate an overall view of students' progress.

\section{Results}

\subsection{First recording submission}

When the students 'emails were received, the audio files were renamed after the sending students and were analyzed based on the intended criteria. The data were tabulated according to the duration of speaking activity time out of planned 30 seconds, number of the words uttered, and lines produced. The average was then, calculated in terms of the three measures. From the total 35 participants, the average speaking time was found to be 19.5 seconds. The average number of lines for each recorded time span was 4 lines. On average, the word count for each recording was 32.4 words. The resulting data are presented in Table 1.

Table 1. Tabulation of the pre and post test data

\begin{tabular}{lcccc}
\hline & $N$ & Length of speaking time & $\begin{array}{c}\text { No. Avg. } \\
\text { Lines }\end{array}$ & $\begin{array}{c}\text { No. Words } \\
\text { Uttered }\end{array}$ \\
\hline Con (pre) & 17 & 19.5 & 4 & 32.4 \\
Con & 17 & 20 & 4 & 33 \\
(post) & & 19.5 & 4 & 32.4 \\
Exp (pre) & 18 & 21 & 4.2 & 36.3 \\
$\begin{array}{l}\text { Exp } \\
\text { (post) }\end{array}$ & 18 & & & \\
\hline
\end{tabular}

The submission process of the audio recorded files for the experimental group went on nonstop during the whole semester. The weekly submission due date was on Wednesdays, i.e., two days after the class session, to give the students convenience and practice time. As already mentioned, the recordings were based on the topics covered in the class discussions, which made the task somehow more familiar to the students who seemed to be a little concerned at the commencement of the study.

\subsection{Final recording submission}

Data from audio files from week 14 of the study were transcribed as needed, tabulated, and analyzed upon receiving. From this set of evidence, considered as the post test, it was shown that the average speaking time in the treatment group was 21 seconds. Students' performance on average contained 4.2 lines, and the average word count was 36.3 per recording. As for the control group, the average speaking time was 20 seconds, their performance on the average contained four lines and the average word count was equal to 33. As observed, analysis of the findings collected from the data does not effectively point to any significant change in the number of words uttered per second. In other words, it seems that the verbal performance of our respondents has not been altered in terms of the words uttered per second between pre and posttest stages. Nonetheless, the respondents reported some benefit from this activity. Eight students pointed out that producing Hand phone-audio recordings served as a reasonable step stone to get engaged in speaking, thinking and thus, enhancing their language use skills in English at least in the form of the words used. Some students reported that their peers produced the script while recording. Some of the respondents regarded this as a hindering factor; others noted that the writing task itself provided them with the opportunity to be more attentive to the forms in speaking and resulted in some form of corrections. As revealed, no significant difference was detected in duration of audio recordings among the participants in pre and posttest stages. Consequently, in order to identify if Hand phonebased audio recording benefited learners and positively impacted the performance in the target language, another strategy was employed to see if Hand phone-based audio recording can be taken as a practical EFL instruction strategy. Four students from the experimental group were randomly invited to speak in front of the class regarding the Hand phone task and assignments. They had no time limitation for their speaking and were free to end their speaking as they wished. On average, the students uttered 41.2 more sophisticated words in 24 seconds. The feedback fabricated from the performances supplied the researcher with the students' use of two major categories of Language Learning Strategies, namely Cognitive and Metacognitive strategies. They were either mental rehearsal of their performance or writing down and learning them by heart which made it possible to rewind, rethink, review, revise, and reword the material if need arise. Majority of students reported writing down their ideas before actual speaking and recording, some others preferred to speak on the spot and just had some form of outlining in their mind.

Regardless of the method they used for their performance, practice was an indispensable and important strategy students used to improve their verbal skills. Prior to sending the audio recorded files, students had the chance to do their best and send the ideal form of their performance. Comparison of the results indicated an increase in speaking time, number of the lines and words produced. This evidence lead the researcher to conclude that the activity more likely improves the quality of their verbal performance in the target language. They were both capable of speaking for a longer duration and use more lexical items in a specified time span. It seems that technology enabled the learners to exploit more effective monitoring of their oral skills. Extra effort students made to prepare their audio recordings and possible writing and 
memorizing of the scripts increased the exposure to language and strategies, via use of dictionaries or other reference sources, and websites. Since rendering a Hand phone recording was an external task, it engaged students with the selection of the appropriate material, their order of presentation and importance of the main idea they had in their minds. All these required students to cater for their own communicative outputs and monitor them. The use of recording feature of the Hand phone made the students to review, evaluate and revise their assignment prior to final submission stage and therefore, to enhance their communicative ability or performance. Although some students found the Hand phone activity challenging at first few weeks, it turned to a manageable and enjoyable assignment to them at later stages. Nearly, all the 18 students of the experimental group believed that recording and sending Hand phone audios was beneficial for developing communicative skills.

\section{Conclusion}

Given the strategies formulated by some educational institutions for developing dynamic distance education(Weber, Yow, \& Soong, 2005), it is suggested that Hand phone technology can serve as a reasonable choice for a mature review of the content. Incorporating Hand phones in EFL curriculum requires further studies, and as the present study revealed learners can use such tools to communicate their views outside their instructional settings. Briefly, the task asked students to produce weekly 30 second Hand phone audio recordings in the target language on a topic already covered in class. The initial and final audios rendered by the 35 learners did not reveal any significant development in their linguistic output, however it gave them the opportunity to get involved in regular expression of their views, monitoring and improving them. The analysis of the results showed that the participants understood the benefits of using audio features of Hand phones to render content, and a few had some achievement in speaking at the same time. Nonetheless, further investigations are needed to explore the extent of improvement. As this research showed, Hand phones can serve as practical devices to empower EFL learners to upgrade their communicative skills in rendering audio-visual content. Language tutors can take advantage of such functions and expand this area of research. In conclusion, as the evidence suggests, Hand phone Technology seems to be beneficial to language learning success. It could be used as an efficient tool in EFL setting, which can make learning process more dynamic, enjoyable and flexible. Although not all the students sent in the whole recorded audios, nearly all managed to take advantage of the feature and develop their verbal performance to some extent. The research also indicated that more access to and practice with the Hand phone as a language learning device, enables the students to enjoy the activity and benefit more from a gadget designed primarily for communication and entertainment to enhance their language learning. This in turn, seems to be based on the students' interest in the digital gadgets and their feeling of self-efficacy in using digital devices as new trends in enhancement of language learning (Shakaramia, Khajehei, \& Hajhashemi, 2013). The association of students' perceptions of their learning environment with self-efficacy was found to be reasonably strong, indicating that the more skillful students feel in the use of digital devices, the more efficiently they learn if that device is used for the purpose of language learning enhancement.

\section{References}

Gass, S. M. (2013). Second language acquisition: An introductory course (4 ${ }^{\text {th }}$ ed.). New York, NY: Routledge. Gromik, N. (2009). Producing cell phone video diaries. In M. Thomas (Ed.), Handbook of research on Web 2.0 and language learning (pp. 259-273). Hershey/New York: Information Science Reference.

Kiernan, P. J., \& Aizawa, K. (2004). Cell phones in task based learning: Are cell phones useful language learning tools? ReCALL, 16(1), 71-84.

Motiwalla, L. F. (2007). Mobile learning: A framework and evaluation. Computers \& Education, 49(3), $581-596$.

Oliver, B., \& Goerke, V. (2008). Undergraduate students' adoption of handheld devices and Web 2.0 applications to supplement formal learning experiences: Case studies in Australia, Ethiopia and Malaysia. International Journal of Education \& Development using Information \& Communication Technology, 4(3).

Pouezevara, S. L., \& Khan, R. (2007). Learning communities enabled by mobile technology: A case study of schoolbased, in-service secondary teacher training in rural Bangladesh Innovative information and communication technology in education and its potential for reducing poverty in the Asia and Pacific region. Asian Development Bank.

Shakaramia, A., Khajehei, H., \& Hajhashemi, K. (2013). Digital Self-Efficacy and Language Learning Enhancement in an Online Setting. Journal of Basic and Applied Scientific Research (JBASR), 3(11), 80-84.

Shudong, W., \& Higgins, M. (2005). Limitations of mobile phone learning. Paper presented at the Wireless and Mobile Technologies in Education, 2005. WMTE 2005. IEEE International Workshop on.

Stockwell, G. (2007). Vocabulary on the move: Investigating an intelligent mobile phone-based vocabulary tutor. Computer Assisted Language Learning, 20(4), 365-383.

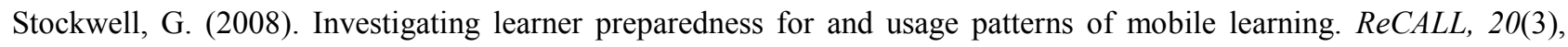
253-270.

Stockwell, G. (2010). Using mobile phones for vocabulary activities: Examining the effect of the platform. Language Learning \& Technology, 14(2), 95-110.

Thornton, P., \& Houser, C. (2005). Using mobile phones in English education in Japan. Journal of computer assisted learning, 21(3), 217-228.

Uzunboylu, H., Cavus, N., \& Ercag, E. (2009). Using mobile learning to increase environmental awareness. Computers \& Education, 52(2), 381-389. 
Weber, I., Yow, K. C., \& Soong, B.-H. (2005). Tuning in to students' mobile learning needs. In A. Kukulska-Hulme \& J. Traxler (Eds.), Mobile learning: A handbook for educators and trainers (pp. 150-156). Oxon: Routledge. 